\title{
Construção de jogo como dispositivo para a aprendizagem colaborativa: algumas estratégias
}

Game design as a device for collaborative learning: initial strategies

Cynthia Macedo Dias, Mestre em Design, Fiocruz, cynthia@fiocruz.br;

Camila Furlanetti Borges, Doutora em Saúde Pública, Fiocruz, camilaborges@fiocruz.br;

Adelyne Mendes Pereira, Doutora em Saúde Pública, Fiocruz, adelyne@fiocruz.br.

\section{Resumo}

Discute-se motivações e resultados da etapa inicial da construção de jogos como dispositivo para ensino e aprendizagem, com foco na colaboração professoresalunos. Esta consistiu na experimentação de jogo desenvolvido por alunos; no debate sobre jogos, suas mecânicas e discursos; e na reapropriação dos saberes do jogar como recursos de projeto.

Palavras Chave: game design, aprendizagem colaborativa, educação profissional em saúde.

\section{Abstract}

This paper discusses the motivation for and results of the preliminary steps in the construction of games as teaching and learning devices. The focus was on teacher/student collaboration, which consisted of an experiment with a game developed by students; the debate about games, their discourses and mechanics; and the reappropriation of knowledge about games as a resource for the project.

Keywords: game design, collaborative learning, health professional education. 


\section{V SILID IV SIMAR \\ PUC-Rio - Dias 28, 29 e 30 de julho de 2015}

\section{Introdução}

A experiência de construção de jogos como dispositivo de ensino-aprendizagem que deu origem ao presente artigo se realiza no âmbito do componente curricular intitulado Trabalho de Integração (TI), presente no Ensino Médio Integrado da Escola Politécnica de Saúde Joaquim Venâncio. Tal componente, inserido na formação integrada nos cursos de nível médio com habilitação técnica em saúde (habilitações em Análises Clínicas e Gerência em Saúde), tem como objetivos principais:

- estimular aprendizagem crítica sobre algum tema específico na área da saúde, buscando construção de conhecimento sobre a prática dos serviços de saúde no contexto do Sistema Único de Saúde (SUS);

- mobilizar a integração de conceitos fundamentais aos conteúdos de eixos teóricos que versam sobre Ciência, Trabalho, Política e Saúde (componentes curriculares de perfil mais teórico);

- iniciar e estimular a prática investigativa no campo da saúde.

Os TIs são realizados com grupos de 10 a 12 alunos, acompanhados por preceptores com alguma experiência de pesquisa no tema proposto. No grupo em questão, propusemos o tema da regionalização dos serviços e sistemas de saúde, trabalhado por meio do dispositivo de desenvolvimento de um jogo. No presente artigo, são discutidas as estratégias iniciais desenvolvidas com a turma e seus fundamentos teóricos. As mesmas tiveram como objetivo introduzi-los a pensar sobre jogos, a fim de prepará-los para viver a construção de jogos como dispositivo para o ensino e a aprendizagem, tendo como foco a colaboração professoresalunos.

\section{Problema/propósito}

No ano de 2013 desenvolvemos uma primeira experiência de construção de jogos com alunos de Ensino Médio integrado ao técnico, na qual construímos com um grupo de oito alunos um jogo de tabuleiro sobre as relações entre agentes públicos, privados e filantrópicos no âmbito do Sistema Único de Saúde (SUS) brasileiro.

Naquela ocasião, verificamos que, ao assumirem a posição de produtores, os alunos refletiram sobre processos, relações, possibilidades e negociações presentes na vida real, com mais engajamento do que na etapa que previa somente o estudo e debate dos assuntos propostos. Durante o processo de construção do jogo, que contou com a introdução de conceitos de game design por meio de oficinas do coletivo Gamerama1, os alunos mobilizaram diferentes saberes e habilidades, demonstrando na narrativa, nas regras e nos discursos embutidos no jogo não só a sistematização de um aprendizado factual ou processual, mas também político em relação ao tema. Verificamos, ainda, a influência da organização espacial no 
fomento ao trabalho em grupo (DIAS et al., 2014). Entretanto, pudemos perceber que a complexidade e abrangência do tema abordado, associada à entrada tardia da discussão sobre jogos, dificultou o engajamento dos alunos, levando a um processo de construção que, embora muito rico, ficou restrito em termos de tempo.

Com base nessas reflexões e avaliações sobre a experiência anterior, tomamos desta vez duas decisões fundamentais: além de propor um tema mais próximo da realidade dos alunos e que já possuía mais material sistematizado, provocar os alunos mais cedo no calendário de aulas para refletir sobre aspectos que embasariam, ao nosso ver, o trabalho proposto de construção de jogos aplicados. Além disso, fizemos aulas expositivas sobre o tema, reconsiderando o lugar da pratica de pesquisa: menos como uma etapa previa à construção do jogo, e mais como uma estratégia inerente ao próprio processo de feitura de jogos, na medida em que a formulação da narrativa e das regras do jogo mobiliza a investigação mais amiúde, sempre de forma orientada e colaborativa. Como esse caminho metodológico nos pareceu ter sido bastante proveitoso para os alunos, e fundamental para que estivessem embasados para as etapas posteriores de desenvolvimento de seu próprio jogo, ainda em fase de conceitualização, é nesses momentos iniciais que nos concentramos na presente comunicação.

A prática partiu, assim, da experimentação de jogo desenvolvido por turma anterior; associado ao debate sobre jogos conhecidos, suas mecânicas e discursos; e a uma reapropriação dos saberes adquiridos no jogar, a fim de constituir uma provocação à construção de saberes que potencializassem o processo de projeto de novos jogos.

\section{Abordagens teóricas}

A proposta de construir jogos como dispositivo de aprendizagem colaborativa consolida e desdobra o trabalho já desenvolvido no NUTED - Núcleo de Tecnologias Educacionais em Saúde - da EPSJV, que busca, unindo pesquisa, ensino e produção tecnológica:

potencializar a relação tecnologia, educação e saúde no sentido da valorização dos processos de formação humana como práxis da liberdade, como autonomia do indivíduo e da coletividade, como consolidação de uma subjetividade crítica capaz inclusive de imaginar outras formas de sociabilidade para além do capital. (EPSJV, 2015)

Jogos são produtos culturais que têm, em si, uma cultura específica, composta de formas e significados. Segundo Brougère (1998), "se aprende primeiro o que se relaciona com o jogo para, em seguida, aplicar os conhecimentos adquiridos para outros campos não-recreativos da vida". Além do conhecimento inerente aos jogos, eles também mobilizam outros tipos de conhecimento, uma cultura geral, que podem ser considerados "pré-requisitos". Esses pré-requisitos são 
necessários não só para o ato de brincar, mas ainda mais na construção de um jogo que depende da aprendizagem, discussão e questionamento dos processos e mecanismos para projetar as metáforas do jogo e a jogabilidade.

A proposta apresentada tem ressonância ainda na defesa de Gee (2008) de que características de aprendizagem presentes em bons jogos também são apoiadas e encorajadas por bons processos de aprendizagem. Alguns exemplos dessas características são: desenvolvimento de fortes identidades; possibilidade de tornar-se produtor e não apenas consumidor; possibilidade de experimentação, teste e revisão de hipóteses; baixas consequências para o erro; customização aos estilos de aprendizagem e jogo do sujeito; sensação de agência, propriedade e controle; e, uma que nos parece fundamental para a formação crítica e política dos alunos, o encorajamento a pensar sobre relações e processos interligados - não eventos isolados, fatos ou habilidades.

Considerando que no contexto em questão o jogo entra como meio e como fim no processo de estudo e pesquisa sobre o tema da regionalização, auxiliando a visualizar, conceber expressar os desafios e potencialidades existentes nessa estratégia de organização do SUS, utilizamos como referência o conceito de "jogos sérios" (serious games) ou "jogos aplicados": jogos que, além de serem divertidos, têm um propósito na vida real. Esses jogos têm sido utilizados, além de educação e treinamento, como produtos que objetivam conscientizar o público sobre causas políticas e sociais (Vasconcellos, 2013).

Percebemos como fundamental articular os estudos sobre o tema proposto com a discussão sobre jogos enquanto produto cultural. A teoria da retórica procedimental, desenvolvida por Ian Bogost (2010), defende que os jogos possuem valores e ideias embutidas em suas regras, constituindo argumentos que são passados aos jogadores, representando formas de funcionamento de processos do "mundo real". Mais do que isso, determinados jogos possuem, mais do que outros, o objetivo final de transmitir de uma mensagem ou mesmo influenciar a mudança de comportamento do jogador a partir da experiência de jogo, estes denominados por Bogost de "jogos persuasivos" (2007).

As autoras Mary Flanagan e Helen Nissenbaum (2014) explicitam e analisam mais profundamente as formas como jogos carregam valores éticos e políticos, nem sempre apenas na narrativa ou nas regras, as formas mais explícitas, mas também em seus componentes tecnológicos, e defendem que os game designers deveriam tornar-se mais conscientes de seu "poder" de transmitir valores ao tomar cada decisão no design de seu jogo.

Evidentemente que, ao carregar valores, os jogos não determinam a compreensão e adesão imediata dos mesmos pelos jogadores: outros estudos amplificam a relação jogo-jogador para considerar um papel ativo do jogador, não só manipulando as peças e regras como também interpretando, questionando, criticando e mesmo criando novas regras e jogos (Vasconcellos, 2013). Entretanto, 
ao considerar jogos como produtos culturais, partes de um currículo cultural maior em que os jovens estão inseridos, é fundamental estender a análise crítica, realizada em relação a outros meios, também aos jogos, e possibilitar a construção reflexiva de jogos por esses mesmos jovens, estimulando o questionamento e a expressão de valores éticos e políticos.

Ao mesmo tempo, em um aspecto mais metodológico, baseamo-nos na defesa de Jesse Schell (2015) de que o game design é uma atividade baseada em tomadas de decisão, e de que "game designer" é um papel, não uma pessoa. O que torna alguém um game designer é tomar decisões sobre aspectos de jogos: projetar jogos. Além disso, ele esclarece que jogos são artefatos que possibilitam experiências, e que pensar como esse artefato pode construir essa experiência deve ser o foco do game designer.

Em termos mais específicos, também utilizamos como referência a ideia de que todos os jogos, por mais triviais que pareçam, podem ser visualizados em termos das estratégias ou padrões de demandas ou padrões de participação que oferecem aos jogadores (Xavier e Protasio, 2009).

\section{Métodos}

Com base nos fundamentos teóricos apresentados, e a fim de estimular os olhar crítico sobre valores e discursos embutidos em diversos componentes dos jogos e o fato de que existem jogos que, mais do que outros, têm como objetivo final a transmissão dessa mensagem ou mesmo a mudança de comportamento do jogador, na primeira aula, depois de apresentarmos os princípios da Regionalização, procedemos à experimentação e discussão sobre jogos e seus discursos. Buscamos interpretar, a partir de uma leitura crítica, possíveis sentidos emergentes das regras, do visual e da narrativa de jogos como "The Mc Donald's Videogame" (Molleindustria, 2006), "Dumb ways to die" (Metro Trains Melbourne, 2013), "Sweatshop" (Littleloud, 2011), "3rd world farmer" (3rd World Farmer Team, 2012) e "Spent" (McKinney, 2011). Ficou claro que todos esses jogos possuem uma intencionalidade que está para além da imersão e diversão do jogador: eles procuram transmitir mensagens sobre temas da realidade e, como repercussão, mudar o comportamento de seus jogadores a respeito desses temas.

No segundo encontro, propusemos à turma jogar o jogo desenvolvido em 2013, com o objetivo de expandir o debate iniciado na aula anterior, discutindo o jogo como possibilidade de representação e metaforização de processos reais, expressão de ideias de seus produtores e disparador de debates; reunindo as turmas para troca de experiências e proporcionando aos alunos a vivência de jogar um jogo desenvolvido por alunos, resultado de um processo pedagógico no âmbito de um Trabalho de Integração, provocando reflexões sobre o tema e o processo de construção do mesmo. Ao mesmo tempo em que encontramos oportunidades de 
melhoria no jogo e em suas regras, o jogo ajudou a colocar em pauta desafios da gestão do SUS, envolvendo os âmbitos público, privado e filantrópico.

A terceira aula foi dedicada à discussão dos jogos "preferidos" dos alunos, buscando provocar outros olhares sobre os jogos, menos com a visão de jogadores em momento de lazer, e mais com a visão de 'desenvolvedores', buscando "estranhar" o jogo e desvendar alguns de seus elementos estruturantes.

Nesse momento, os alunos trouxeram jogos com os quais tem mais familiaridade, como Truco, Buraco, War e Banco Imobiliário. O estranhamento desses jogos produziu o levantamento de atributos e estratégias que foram confrontadas em relação à sua pertinência para o tema da regionalização.

- Buraco: um jogo que requer estratégias de comunicação, às vezes envolvendo blefes, e combinação de cartas para formação de sequências. Mobiliza cooperação entre os membros da dupla, e competição entre as duplas.

- Truco: mobiliza estratégias de comunicação e pactuação interna dos times

- War: um jogo construído baseado em um cenário de "mapa-mundi" em que os jogadores devem construir estratégias para anexar territórios de outros jogadores.

- Banco Imobiliário: trabalha com acumulação de dinheiro e propriedades, além de elementos de sorte (representado pelo uso dos dados e pelo componente "sorte ou revés").

Ao final da aula, a reflexão girava em torno da questão: "Se a regionalização fosse um jogo, como poderíamos caracterizá-lo?". Vale considerar que uma parte da teoria de ciência política, de fato analisa uma diretriz como a regionalização considerando-a envolvida em um jogo de interesses. Nessa perspectiva, algumas considerações dos alunos revelavam tanto uma apropriação inicial do tema quanto de possíveis atributos do jogar. Destacamos algumas considerações e metaforizações produzidas nessa aula:

- gestores de regiões de saúde, seja em nível estadual, municipal, ou mesmo outros atores políticos participantes diretos dos conflitos de regionalização, como diretores de estabelecimentos de saúde e prestadores privados, podem ter suas funções e desafios estudados a fim de figurarem como personagens da narrativa de um jogo;

- a depender do cenário da narrativa, esse personagens podem ser escolhidos e desempenhar funções mais ou menos similares às da vida real, levantando um leque de desafios que se coloca à regionalização em saúde; 


\section{O V SILID IV SIMAR \\ PUC-Rio - Dias 28, 29 e 30 de julho de 201}

- a narrativa pode ser desenvolvida de modo a retratar algo mais próximo da realidade e mobilizar a competição entre os personagens/jogadores ou de modo a estimular a experimentação do que seriam modos de gestão mais desejáveis, construindo um jogo que induza à cooperação entre os jogadores/personagens;

- qualquer que seja opção da narrativa - competição ou cooperação - há elementos que podem compor o cenário e caracterizar a base material do jogo, como recursos financeiros, estabelecimentos e equipamentos de saúde, recursos humanos, procedimentos técnicos e indicadores de saúde, que podem ate assumir o papel de metas/objetivos dos jogadores;

- dados da situação de saúde da região (como necessidades de saúde, composição demográfica, dados epidemiológicos, condições socioeconômicas, etc), podem ser elementos de objetivos do jogo ou mesmo embutir o elemento aleatório (sorte ou revés);

- os objetivos do jogo podem retratar quais os elementos necessários à composição de uma região de saúde, bem como estimular habilidades requeridas de um gestor, como o planejamento, a eleição de critérios e prioridades para a distribuição de recursos, etc;

- por fim, se a narrativa do jogo for construída não do ponto de vista do gestor, mas do ponto de vista do usuário do sistema, a trajetória do paciente pode inserir novos elementos talvez mais subjetivos (satisfação de necessidades, motivação, etc) ou espaciais (traduzindo desafios da acessibilidade aos serviços de saúde).

Em associação com essas aulas iniciais, foram realizadas leituras, discussões em grupo e debates com uma convidada escolhida em função da experiência no processo de regionalização no estado do Rio de Janeiro. Em seguida, foram realizadas as oficinas Gamerama, em que os alunos tiveram contato com conceitos mais sistematizados de design e game design e puderam começar a experimentar na prática a vivencia de serem game designers, construindo jogos simples de dados, de cartas e de tabuleiro. Nesse último rol, propusemos que eles buscassem associar a percepção da inserção de valores e sentidos nos jogos com os conteúdos estudados sobre regionalização, e os resultados foram muito ricos, demonstrando compreensão e apropriação de ambos os aspectos, além de elementos conceituais das próprias oficinas, relativos ao game design.

\section{Considerações}

Na primeira experiência de construção de jogos, de certo modo, a entrada tardia da discussão sobre jogos deveu-se a uma percepção da importância de induzir os alunos a um processo de pesquisa sobre o conteúdo do tema antes de mergulhar 
no desenvolvimento, como se houvesse uma ordem logica em colocar a pesquisa e apropriação do conteúdo antes do estudo da tecnologia mediadora (o jogo). Entretanto, na experiência relatada neste artigo, pudemos perceber a riqueza da inserção precoce da discussão e análise de jogos para a continuidade e produtividade do processo de aprendizagem e construção do jogo, reposicionando a pesquisa e aprofundamento no conhecimento teórico como parte integrante do trabalho de game design.

Com base nos relatos dos alunos, tanto a discussão sobre discursos em jogos quanto a experiência de jogar o jogo da outra turma parecem ter contribuído com as oficinas Gamerama para construir a compreensão de que jogos possuem valores que podem ser transmitidos aos jogadores, e para auxiliar os alunos a se enxergarem como potenciais designers de jogos, bem como verificar que um jogo com a temática da saúde poderia ser divertido e ainda assim explicitar relações existentes entre atores sociais envolvidos na oferta de serviços de saúde no contexto do SUS no Brasil.

Ao jogar o jogo da turma anterior, que mobilizava um conteúdo técnico que eles já dominavam pelo menos parcialmente - alguns aspectos das disputas de interesses no interior do SUS - eles tiveram maior facilidade de analisar e questionar as regras e intencionalidades do jogo em pauta. Como consequência, os alunos chegaram à conclusão de que aquele era um jogo que requeria conhecimentos prévios, e portanto acessíveis apenas a quem já tivesse estudado sobre o SUS. Passaram a questionar, desde então, qual seria seu público e objetivo, concluindo consensualmente que seu jogo final seria pensado para um público leigo, buscando mais divulgar o SUS do que construir um jogo de consolidação de conhecimento (perfil do jogo anterior), compreendendo a necessidade de esclarecimentos sobre direitos da população usuária.

O trabalho nos mostrou ainda que, como desenvolvedores de jogos, os alunos se apropriaram dos conteúdos e os reconstruíram através de olhar potencializado na colaboração. A aprendizagem e vivência do processo de game design culminarão ainda em novos momentos de pesquisa, como meio para aprofundar, sistematizar e decidir como comunicar os conhecimentos da turma sobre o tema por meio de regras e elementos de jogo.

\section{Notas}

i Gamerama é uma oficina de criação e desenvolvimento de jogos analógicos e digitais. Suas sete modalidades foram planejadas para atender a diferentes públicos e demandas. Desde 2007, são realizadas em escolas e universidades. Mais que uma oficina sobre metodologia de criação de jogos, o Gamerama estimula a criatividade e o trabalho em equipe, motiva para a aprendizagem e promove a integração entre seus participantes. Gamerama conjuga teoria e prática, coloca os participantes em atuação na solução metodológica de problemas das mais variadas naturezas e promove a satisfação de fazer. Para mais informações, acesse http://www.gamerama.net.br. 


\section{SILID IV SIMAR}

\section{Referências Bibliográficas}

BOGOST, Ian. Persuasive Games: the expressive power of videogames. Cambridge, MA: The MIT Press, 2010.

BROUGERE, Gilles. A criança e a cultura lúdica. In: Rev. Fac. Educ., São Paulo v. 24, n. 2, July 1998. Disponível em: http://dx.doi.org/10.1590/S010225551998000200007. Acesso em 28 jul. 2015.

DIAS, Cynthia M.; BORGES, Camila F.; REGADAS, José Victor L.; XAVIER, Guilherme de A.. "Playing with health": game design methodology for public health education. Serious Games and Applications for Health (SeGAH), 2014 IEEE 3rd International Conference on. 2014. Pages: 1 - 8, DOI: 10.1109/SeGAH.2014.7067083

EPSJV. Tecnologias Educacionais em Saúde (website). Escola Politécnica de Saúde Joaquim Venâncio, Fiocruz. Disponível em: http://www.epsjv.fiocruz.br/index.php?Area=AreaTematica\&MNU=NUTED\&Area_Nu $\mathrm{m}=207$. Acesso em 28 jul. 2015.

FLANAGAN, Mary; NISSENBAUM, Helen. Values at Play in Digital Games. Cambridge, Massachussets; London, England; The MIT Press, 2014.

GEE, James Paul. Being a Lion and Being a Soldier: Learning and Games. In: J. Coiro, M. Knobel, C. Lankshear, \& D. Leu (Eds.), Handbook of research on new literacies (pp. 1023-1036). New York: Lawrence Erlbaum Associates, 2008.

SCHELL, Jesse. The Art of Game Design: A Book of Lenses. $2^{\text {a }}$ edição. Pittsburgh, Pennsylvania, USA: Carnegie Mellon University and Schell Games, 2015.

VASCONCELLOS, Marcelo. Comunicação e Saúde em Jogo: os videogames como estratégia de promoção da saúde. 2013. Orientadores: Inesita Soares de Araújo e Joost Raessens. Tese (Doutorado) - Instituto de Comunicação e Informação Científica e Tecnológica em Saúde, Pós-graduação em Informação e Comunicação em Saúde. 293 f. Fundação Oswaldo Cruz, Brasil, 2013.

XAVIER, Guilherme; PROTASIO, Arthur. Decomposição Lúdica do Jogar. In: SBGames 2009 VIII Simpósio Brasileiro de Jogos e Entretenimento Digital, 2009, Rio de Janeiro. Anais SBGames 2009. Rio de Janeiro, 2009. 